\title{
Exploration of the Rural Construction Mode Based on Sociological Research-Take Longma Town in Enshi County of Hubei Province for Instance
}

\author{
Chao Xie and Xiaofeng Li
}

\begin{abstract}
With the continuous development of the new urbanization progress, building beautiful villages has become the most important historical mission for the contemporary Chinese new socialist countryside, while the rural construction is paid more and more attention to by the academic circle. However, the countryside has met numerous obstacles in the real rural construction and gradually get into the trouble of "neither look like a city or a village". How to eliminate the drawbacks of the past rural construction? This article has taken the Longma Town in Enshi of Hubei Province for example. Based on the sociological research and planning practice, this article will proceed from the social, economical, cultural and environmental benefits and explore the suitable rural construction mode for the era development and ecological settlement.
\end{abstract}

Index Terms-Mode, rural construction, sociological research.

\section{INTRODUCTION}

China is a vast agricultural country. How to solve the problem of "agriculture, rural areas and the farmers" and improve the long-term backwardness has been the essential issue for China's sustainable development. In 2008 and 2012, prime minister Li Keqiang had been to Longma and Qingbao twice for inspection, and he proposed the construction reqirement of "return the grain plots to forestry; move for poverty alleviation; build towns for immigrants; adjustment of industrial structure" during the second visit on Dec. 29th, 2012. Enshi is the test site for the social and economical development of the minority in Wulin Mountainous Area. The construction of Longma Town, as the startup project of the comprehensive poverty alleviation reform, has certain model significance and is a beneficial attempt and positive exploration for the construction for the rural areas.

We are exploring whether there is a way to keep the original ecological features and the human landscape and inherit the traditional folk-customs. And we are looking forward to realize the social, economical, cultural and environmental benefits in the impoverished mountainous are. Our work starts with the investigation of the current status of Longma Town in Enshi.

Manuscript received July 10, 2014; revised September 12, 2014. This work was supported in part by Specialized Research Fund for the Doctoral Program of Higher Education under Grant No. 20120142110009.

The authors are with School of Architecture and Urban Planning, Huazhong University of Science and Technology, China (e-mail: xiebochao@gmail.com,lixf523@163.com).

\section{The Social InVESTigation ON PRESENT LONGMA TOWN}

\section{A. What is like?}

Longma Village is in the northwest of Longfeng Town, which is 37 miles from Enshi Prefecture. The old highway traverses all the district and the new highway will be planned to traverse the north bank of Qingshui River. The village has 7 administrative villages with about 18,000 people and 128 square miles. In 2002, the Longma Village was canceled and merged into Longfeng Town (see Fig. 1). The basic ecological condition of this place is "huge mountains and few people". The average farmland resources for per person is 1 to 2 acre of land in the plain area while 3 to 5 acre of land in the mountainous area.

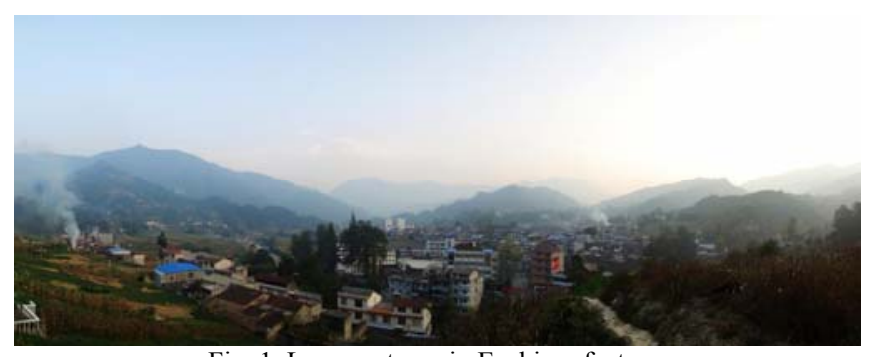

Fig. 1. Longma town in Enshi prefecture.

First of all, we should focus on who are living in this town. There are mainly two types: those who have stable residences, long living experiences and familiar social circle, which called "town folks"; the other type refers to those who carry out commercial activities from the village to the town, which called "villagers".

The villagers can categorized into three types: 1) the owner of the business works along the Longma Street and the owner of the individual workshops from each villages; 2) the other residents outside the Longma Street; 3) some special groups of people, which includes some local forces. However, there are two types of the villagers: 1) the villagers who go to the market of Longma Town periodically; 2) the villagers who move to the town temporarily because the children go to the local schools. Thus, the unique economic and social character of Longma Town is its negotiability. Those who originally lived in the mountainous areas tend to move to the town or more convenient places (see Fig. 2). While shorten the long distance between the public facility and the basic facility for the local villagers and cut down the cost for all the facilities become the most urgent problem to solve for them.

\section{B. What is Going to Be?}

Mr. Fei Xiaotong had investigated the market towns with 
productive characteristics in the southern part of Jiangsu Province and called them "productive town". The business in Longma Town tend to be family-run workshops and they have consumption type, so it is called "consumptive town". The construction design for Longma Town can be two directions: First, continuously invest capital into the town; second, explore the uniqueness of the town to attract investment, such as develop local resources which include the tourism resource. The former design is transfusion-typed construction mode, and we all know that it is not sustainable; the latter one is creation-typed mode. Obviously, Longma Town needs the latter one for its construction.

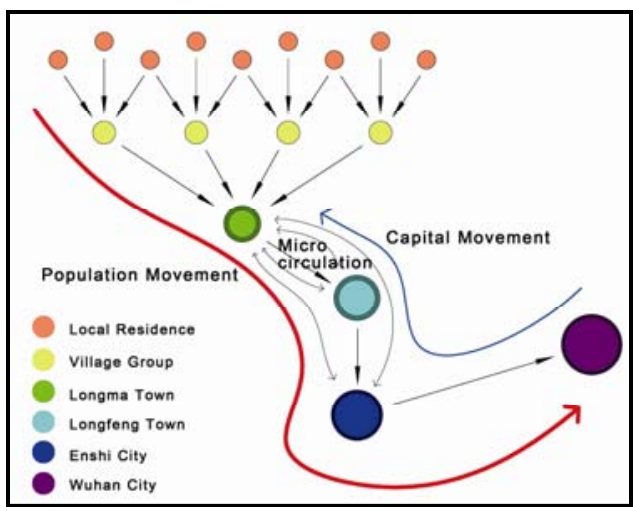

Fig. 2. The mobility of population and capital.

Therefore, the construction for Longma Town needs to seize the dialectics, which is "build up well, but not so well; make it centralized, but not so centralized". "Build up well" refers to provide everyone in town a nice place to live in, especially with the strengthening and perfecting education, medical care, government service and market function; but the town can not "build up so well" to prevent those who intend to leave from staying after the construction. Longma Town is only an intermediate link in the progress of villagers moving to cities, and it is part of the urbanization. The so-called "centralized" refers to the willingness of moving to places with better public services and infrastructure. However, "make it not so centralized" because not every villager can afford the cost and follow-up risks after the construction.

\section{How to Build up?}

When facing with the problems of lands, house property, family income, nursing, the order of population mobility and the occupation of public resources, how to construct the town? First of all, the appropriate land planning and construction planning should be made to meet the local needs. Secondly, make detailed plans and execute solution for Longma Town to carry out the essential planning construction. Thirdly, update the production condition and basic infrastructure in the mountainous area. Fourthly, organize the local farmers and enhance the relationship between them [1].

\section{The Problems AND ThOUGHTS DURING CONSTRUCTION}

\section{A. The Problems and Presentations}

The initial one is the alienation of the rural landscape. The formation of the rural settlement is a nature process, but the city-oriented planning method makes the construction for new villages strong sense of a city not a village. Huge amounts of renovated communities are coming out in the rural ares. Then, the problem is the homogenization of the folk customs. In the progress of urbanization, the traditional infrastructure and living condition can no longer meet the modern life. The countryside accepts the urban civilization passively, some traditional villages are ruined. Instead, the replica-like new villages and exotic towns are made everywhere. The traditional culture and dynamic customs are nibbled up. Thirdly, the issue is the weakening of the traditional farming. Thousands of the young labor force leave for the city for a living, which makes the villages full of the youth and the old.

\section{B. The Background and Conditions}

1) Geographic environment. In Longma area, the Qingshui River is surrounded by mountains, which forms the unique landscape of terraced fields. The road to Qingbao is very magnificent with great greening but steep hills.

2) Humanity history. The "Salt-Tea Trail" in Sichuan-Chongqing-Hubei area is the lifeblood road for improving the local economy and social development, and it is also the historical evidence of the cultural communication between nations. Longma Town is the most important market town in the Salt-Tea Trail. The local residences are placed along the vital highway, its construction also represents the national characteristics of Tujia and Miao.

3) Construction Style. The historical construction style mainly concentrate along the Jiangshe Road beside the Qingshui River with the park wood structure of 1 to 2 storeys. Jiangshe Road is part of the Salt-Tea Trail and it is also the main commercial road in Longma. It keeps the flagstone road and the original structure is remained well. However, some buildings have serious problems due to the long construction time. The old Shuanglong Road is the main road across the town, the buildings along the road represent obvious time-pertaining [2]. The main public buildings mainly centralize along the main road, most of them are 5-storeys. The self-constructed buildings of the local people are 2 to 3 storeys with brisk-stone structure.

\section{The Architectural Positioning}

The initial target for Longma's construction should be "improve people's livelihood, improve poverty alleviation and make resettlement, develop the production activity". Starting with renovating the local environment, make settlements for the immigrants, enhance the infrastructure construction and the public service, and try to build up a field town which is beneficial for both living and tourism with unique Tujia characteristics.

1) Improve the service. The main purpose for Longma's construction is to make the town full of service function. Thus, the initial thing in a short time should be provide the public service and meet the needs for the local farmers, villages, agriculture and peasant-workers.

2) Explore the uniqueness. As a part of the Salt-Tea Trail, Longma Town has great natural landscape which means it has the potential for tourism. However, the basic conditions is not outstanding due to the lack of investment. 
3) Appropriate control. The current Longma Town has a balanced population and the natural environment.
Control the construction scale and strength appropriately should be paid much attention to.

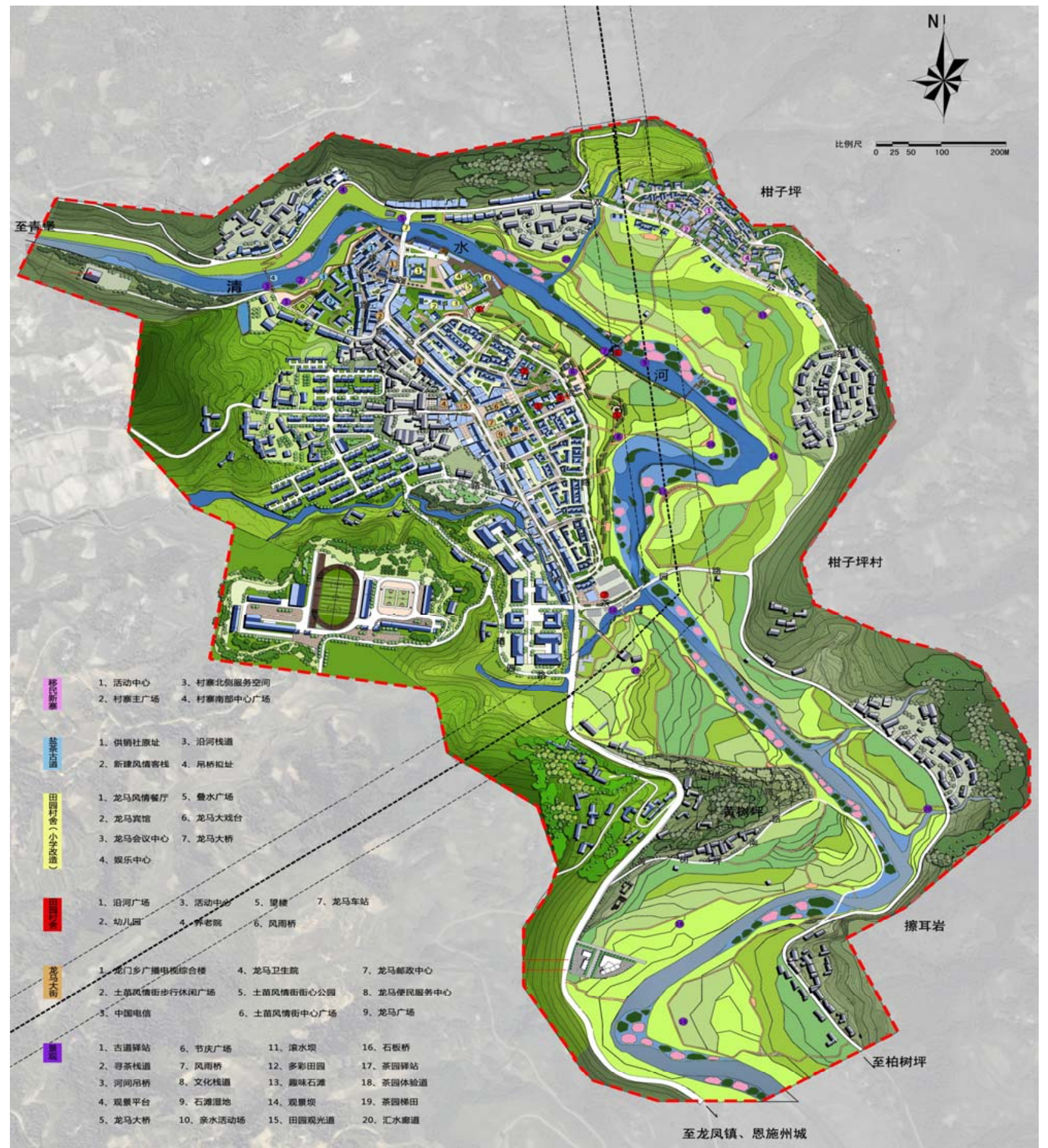

Fig. 3. The overall planning of Longma town.

\section{Construction Strategy}

1) Adjust measures to local conditions, take overall plans and make both short-term and long-tern targets. As Longma has the advantage of strategic location, ecological resources, unique Tujia folk custom and the historical Salt-Tea Trail, it had the long-term potential for tourism investment.

2) Make rational layout and orders. In the space layout, we should respect the original formation of the space. By analyzing the current situation and topographic feature, establish the overall space structure of "concentrate appropriately and make dispersed layout".Guide the villages to take part in the construction. The construction of Longma Town is the reply for the mountainous settlements. Especially in the renovation of Longma Street and the Salt-Tea Trail. In case of excessive constructions, by investigating the willingnesses of the local people and their life styles, following the principle of "economical application, easy operation and keep the historical marks", the construction has the ratings for the buildings according to the building age, storeys and the structure. During the renovation, the buildings of different ages have been kept its original features [3]. 


\section{The CONSTRuction MOde In LONGMA TOWN}

\section{A. Location}

Select the "One Street and Four Communities" ( Longma Street,Salt-Tea Trail, field house, Longma Primary School, Immigrant New Village) as the research subject. According to the specific characteristics, the targeted construction methods are provided (see Fig. 3).

\section{B. Design Principle}

1) Ecological Principle: Respect the nature is the basic starting point in the planning. Decrease excavation, renovate the current landscape appropriately, save the land resource and organize the drainage work, especially on the natural landscape along the river.

2) Cultural Principle: Start with the cultural notion of keeping both renovation and conservation, highlight the cultural merits of Longma Town and combine the traditional culture and modern live, and create the dynamic atmosphere.

3) Adaptive Principle: Fully consider the adaptive problems during the construction and select the renovation scale and means appropriately to make sure the rationality and exploitativeness.

4) Overall Principle: The planning should consider both long-term and short-term benefits [4].

\section{Construction Method}

1) Abundance: Longma Street. The Longma Street lays across the town from south to north with 800 metres. It is the through highway currently with mixed architectures along the road. According to the overall planning design, the through highway will be altered to the new Shuanglong Road in the north bank of Qingshui Road, which makes the Longma Street less function of traffic. Instead, the road will be more commercial. The current residents along the street has reached 170, among them, about 110 residents are commercial tenants, which means the cost of the movements for them are extremely high. However, as the main road locally, the architecture feature should be renovated and the spaces should be updated. Applying both the local resident's self-constructed activities and the renovation plan, increase the activity spaces for the local residents along the street, replace the landscape in some important intersections for improving the overall space quality of the street.

2) Inspiration: Salt-Tea Trail. It is the most completely protected district among all the historical sited in Longma Town with obvious traditional business road. The buildings present the pattern of "front shop and back house", the counters of the shops along the streets and the completed stone drainage system are revealing the past glories. The buildings on one side is facing the street with another side facing the river, which reflect both the natural and historical landscape. During the renovation and protection, change the spaces backwards the street and merge the commercial, living and tourism functions into this area again. By connecting the street space and the river space, the architecture space will be more vivid.

3) Adaptation: Field house. In order to meet the development of Longma Town, the "adaptation" should be the construction method in this are. The road system in the new construction area should follow the original contour line. To control the construction strength and keep the field landscape along the river at the most.

4) Greening: Longma Primary School. The original Longma Primary School will be moved to the southwest of the town, the campus left behind will be used as the public space for this area. The campus will be opened to the Longma Street, filed house and the new roads, which makes this area more use of public lives and tourism investment. According to the practical situation of the place, "greening" is the renovation method. By building the ecological roof between the playground the and dining hall, a ecological square will be made (see Fig. 4).

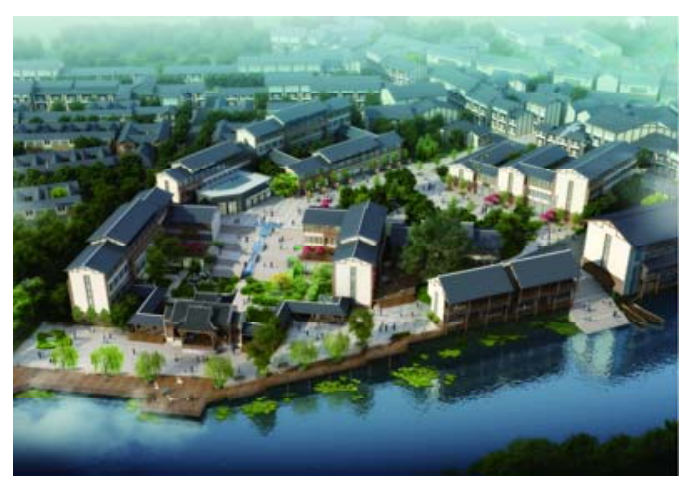

Fig. 4. The transform effect picture along the river.

5) Respect: Immigrant New Village. As the demonstration plot for immigrant in the north bank of Qingshui River. To select the site in the foot of the mountain and to face with the town, is to respect the traditional building in the mountainous areas. The construction principle is "module design, regional features, high-quality construction, overall management and automatical adjustment".

\section{Landscape Design}

Apply the landscape design method of "from up to down", to pursue the origin and keep the original rural cultures and settlements. Apply the local materials and construct the rural landscape with distinct characteristics. In order to continue the rural feelings, by protecting the mountain, river, and making afforestation, ploughing the fields, construct the roads and house, to emerge the Tujia culture into the construction of the landscape environment. Using the river to bunch all the views and establish cultural activity places along the river landscape. In the meantime, use the Tujia elements in the architectural design for presenting the willingness of "seeing the mountain and river and memorializing the nostalgia" by the local people (see Fig. 5 and Fig. 6)

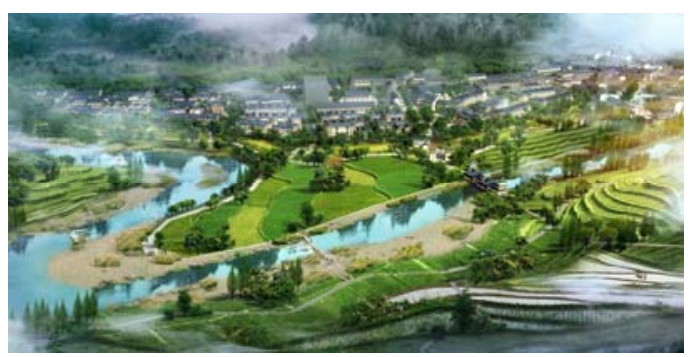

Fig. 5. Scenograph of dwelling and field. 


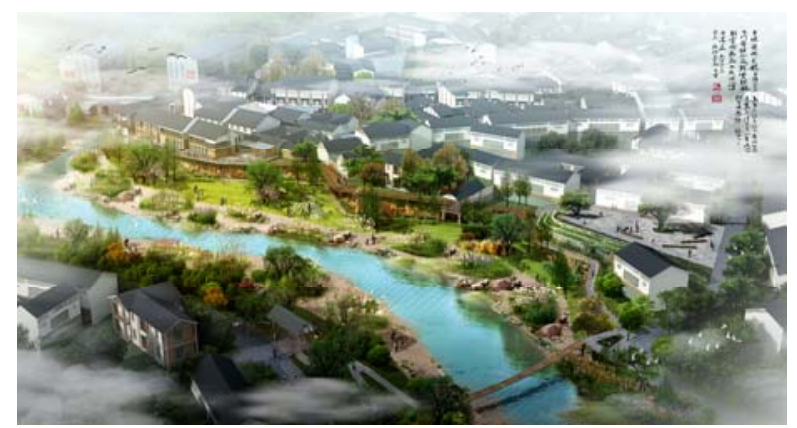

Fig. 6. Scenograph of the old road.

\section{CONCLUSION}

The construction for rural areas concerns the complex issues of agriculture, farmer and rural area, the architecture subject cannot solve all the problems and more subjects should be considered. We cannot regard the complex relationship between rural architecture and rural economy, land system, rural resources, life style, cultural notions, construction method as the simple relationship between pattern and space [5]. The construction mode for beautiful villages should be originated from the real rural lives and place for presenting the relationship between space pattern and living pattern.

\section{REFERENCES}

[1] X. F. He, The future for the villages, Ji'nan: Shandong People's Press, 2007.

[2] X. F. Li and G.-Y. Tang, Hubei and Hunan dwellings, ed. Beijing: Architecture \& Building Press, 2009.

[3] X. F. Li, Vernacular architectural-Interdisciplinary Research Theory and Methodology, Beijing: China Architecture \& Building Press, 2005.

[4] W. Q. Lin, "On the planning innovation in the new countryside construction," Planner, vol. 2, pp. 5-7, 2007.

[5] Y. He, W. W. Sun, and L. Ma, "Rural construction, as a notion and methodology," Journal of Architecture, vol. 4, pp. 19-22, 2011.

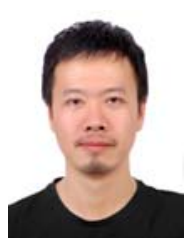

Chao Xie was born in Jiangxi Province, China on July $2^{\text {nd }}, 1985$. He received his bachelor degree in 2007 and he received his master degree in 2010 from Architecural Design in Nanchang University, Nanchang City, China. And he is a Ph.D. student with the pathway of architectural theory in Huazhong University of Science and Techonology, Wuhan City, China. 